\title{
Analisis Prakiraan Kebutuhan Energi Listrik di Provinsi Jambi Tahun 2019-2040 Menggunakan Model DKL 3.2 dan Simulasi Perangkat Lunak LEAP (Long-Range Energy Alternatives Planning System)
}

\author{
Bima Tondi Innatta Harahap ${ }^{1}$, Nehru ${ }^{1}$, dan Oki Saputra ${ }^{1}$ \\ ${ }^{1}$ Program Studi Teknik Elektro, Fakultas Sains dan Teknologi, Universitas Jambi, Indonesia \\ Email: tondiharahap17@gmail.com, nehru@unja.ac.id, okisaputra@unja.ac.id
}

\section{Info Artikel}

Diterima: 2 September 2020

Disetujui: 21 April 2021

Dipublikasikan: 31 Agustus 2021

\section{Alamat Korespondensi: tondiharahap17@gmail.com}

Copyright (C) 2021 Jurnal Engineering

This work is licensed under the Creative Commons Attribution International License (CC BY 4.0).

\begin{abstract}
Abstrak:
Penggunaan energi listrik yang setiap tahun meningkat harus diantisipasi sedini mungkin supaya energi listrik dapat tersedia dalam jumlah yang cukup dan dengan harga terjangkau. Cara mengantisipasi hal tersebut salah satunya adalah prakiraan kebutuhan energi listrik. Tujuan penelitian ini adalah menganalisis serta membandingkan pemenuhan energi listrik dari prakiraan kebutuhan energi listrik di Provinsi Jambi dengan model DKL 3.2 dan simulasi perangkat lunak LEAP. Dalam penelitian ini, data yang dipakai adalah jumlah pelanggan energi lisrtik, konsumsi energi listrik, pembangkit yang tersedia saat ini dan potensi pembangkit baru. Berdasarkan perhitungan, pertumbuhan jumlah pelanggan energi listrik Provinsi Jambi tahun 2019-2040 menggunakan model DKL 3.2 mengalami peningkatan yang lebih tinggi dibandingkan simulasi LEAP. Pertumbuhan konsumsi energi listrik model DKL 3.2 dan simulasi LEAP memiliki perbandingan yang tidak terlalu besar. Perbandingan tersebut dapat dilihat pada perhitungan MAD, MSE, RMSE dan MAPE.
\end{abstract}

Kata Kunci: DKL 3.2, LEAP, Kebutuhan Energi Listrik

\section{Pendahuluan}

Meningkatnya konsumsi energi listrik suatu daerah yang salah satunya diakibatkan pertumbuhan pelanggan energi listrik memiliki pengaruh besar terhadap kebutuhan energi listrik. Jumlah pertumbuhan pelanggan Provinsi Jambi per sektor (rumah tangga, bisnis, sosial dan industri) tahun 2012 hingga 2018 mengalami pertumbuhan rata-rata sebesar 7,68\% dan konsumsi energi listrik di Provinsi Jambi per sektor tahun 2012 hingga 2018 mengalami pertumbuhan dengan rata-rata sebesar 6,02\% (PLN, 2019).

Energi listrik yang tersedia di Provinsi Jambi berasal dari 94 pembangkit yang tersebar yang dimiliki PT. PLN, EBTKE (Energi Baru, Terbarukan, dan Konservasi Energi), IO (Izin Operasi), dan IPP (Independent Power Producer) dengan total kapasitas 484,49 MW, daya mampu sebesar 404,96 MW. Total energi yang diproduksi sebesar 108,66 GWh dengan rugi-rugi daya sebesar 10,9\% pada tahun 2018 (Kementerian ESDM, 2019). 
Penggunaan energi listrik yang setiap tahun meningkat harus diantisipasi sedini mungkin supaya energi listrik dapat tersedia dalam jumlah yang cukup dan dengan harga terjangkau. Cara mengantisipasi hal tersebut salah satunya adalah prakiraan kebutuhan energi listrik. Prakiraan adalah seni dan ilmu untuk memprediksi peristiwa masa depan. Prakiraan melibatkan pengambilan data historis dan memproyeksikannya ke masa depan dengan semacam model matematika dan bisa menjadi prediksi subjektif atau intuitif (Heizer, 2011).

\section{Metode Penelitian}

A. Prakiraan Kebutuhan Energi Listrik Dengan Model DKL 3.2

Model DKL 3.2 yaitu suatu model yang disusun dengan menggabungkan beberapa model seperti ekonometri, Trend, dan End-use dengan pendekatan sektoral. Pendekatan sektoral yaitu suatu pendekatan dengan mengelompokan pelanggan menjadi 4 sektor (rumah tangga, bisnis, umum, dan industri). Data kelistrikan yang digunakan merupakan data pemakaian energi listrik selama 7 tahun terakhir yang dilihat dari sisi konsumen PLN. Setelah pengumpulan dan pengolahan data maka data tersebut akan di masukan ke dalam model DKL 3.2.

a. Sektor Rumah Tangga

Jumlah Pelanggan Rumah Tangga $=P R T_{-1}\left(1+C F H \times \frac{g E}{100}\right)$

Konsumsi Listrik RT $=E \cdot R T_{-1}\left(1+e R T \times \frac{g E}{100}\right)+\Delta P e l . R T \times U K$

Elastisitas $(\mathrm{eRT})=\frac{\text { Pertumbuha } \mathrm{n} \text { energi rumah tang ga }}{\text { Pertumbuha } \mathrm{n} \text { PDRB total }}$

$\mathrm{CFH}=\frac{\text { Pertumbuha } \mathrm{n} \text { pelanggan } \mathrm{RT}}{\text { Pertumbuha } \mathrm{n} \text { pelanggan } \mathrm{RT}}=1$

b. Sektor Industri

Jumlah Pelanggan Industri $=P I_{-1}\left(1+C F I \times \frac{g I}{100}\right)$

Konsumsi Listrik Industri $=E . I_{-1}\left(1+e I \times \frac{g I}{100}\right)$

Elastisitas Industri $(e I)=\frac{\text { Pertumbuha } n \text { energi industri }}{\text { Pertumbuha } n \text { PDRB total }}$

$\mathrm{CFI}=\frac{\text { Pertumbuha } \mathrm{n} \text { pelanggan } \text { Industri }}{\text { Pertumbuha } \mathrm{n} \text { pelanggan } \mathrm{RT}}$

c. Sektor Bisnis

Jumlah Pelanggan Bisnis $=P B_{-1}\left(1+C F B \times \frac{g B}{100}\right)$

Konsumsi Listrik Bisnis $=E \cdot B_{-1}\left(1+e B \times \frac{g B}{100}\right)$.

Elastisitas Bisnis $(e B)=\frac{\text { Pertumbuha } n \text { energi bisnis }}{\text { Pertumbuha } n \text { PDRB total }}$

$\mathrm{CFB}=\frac{\text { Pertumbuha } \mathrm{n} \text { pelanggan Bisnis }}{\text { Pertumbuha } \mathrm{n} \text { pelanggan } \mathrm{R} T}$ 
d. Sektor Publik

Jumlah Pelanggan Publik $=P P_{-1}\left(1+C F P \times \frac{g P}{100}\right)$

Konsumsi Listrik Publik $=E . P_{-1}\left(1+e P \times \frac{g P}{100}\right)$

Elastisitas Publik $(e P)=\frac{\text { Pertumbuha } n \text { energi publik }}{\text { Pertumbuha } n \text { PDRB total }}$

$\mathrm{CFP}=\frac{\text { Pertumbuha } \mathrm{n} \text { pelanggan Publik }}{\text { Pertumbuha } \mathrm{n} \text { pelanggan } \mathrm{RT}}$

Keterangan :

$P R T_{-1} \quad=$ Jumlah Pelanggan RT Tahun sebelumnya

$\triangle P e l . R T=$ Delta Pelanggan Rumah Tangga

$U K=$ Unit Konsumsi (KWh/Pelanggan)

$P I_{-1} \quad=$ Jumlah Pelanggan Industri Tahun sebelumnya

$P B_{-1} \quad=$ Jumlah Pelanggan Bisnis Tahun sebelumnya

$P P_{-1} \quad=$ Jumlah Pelanggan Umum Tahun sebelumnya

$g E \quad=$ Pertumbuhan PDRB total

$g I \quad=$ Pertumbuhan PDRB Industri

$g B=$ Pertumbuhan PDRB Bisnis

$g P=$ Pertumbuhan PDRB Umum

$E R T_{-1} \quad=$ Jumlah Energi Listrik RT Tahun sebelumnya

$E I_{-1}=$ Jumlah Energi Listrik Industri Tahun Sebelumnya

$E B_{-1} \quad=$ Jumlah Energi Listrik Bisnis Tahun Sebelumnya

$E P_{-1} \quad=$ Jumlah Energi Listrik Umum Tahun Sebelumnya

$\mathrm{CFH}=$ Faktor Pelanggan Rumah Tangga

CFI = Faktor Pelanggan Industri

$C F B=$ Faktor Pelanggan Bisnis

CFP = Faktor Pelanggan Publik (Dewayana, 2011)

B. Perangkat Lunak LEAP (Long-range Energy Alternatives Planning System)

LEAP (Long-range Energy Alternatives Planning System) adalah salah satu perangkat lunak yang sangat komprehensif dalam melakukan perencanaan energi. LEAP dirancang unuk dapat bekerja sama dengan produk Microsoft Office ( Word, Excel, Power Point) sehingga mudah untuk impor, ekspor dan menghubungkan ke data serta model yang dibuat di tempat lain. Perancang program aplikasi ini adalah dari Stokholm Environment Institute (SEI) dan memiliki komunitas yang saling berinteraksi yaitu COMMEND (Community for Energy Environment and Development). LEAP bekerja berdasarkan asumsi skenario yang pengguna inginkan, skenario tersebut didasarkan pada perhitungan dari proses konversi bahan bakar menjadi energi hingga energi tersebut dikonsumsi masyarakat. LEAP merupakan model yang mempertimbangkan penggunaan akhir energi (pendekatan end-use), sehingga memiliki kemampuan untuk memasukkan berbagai macam teknologi dalam penggunaan energi (Suhono, 2010). 


\section{Ketepatan Hasil Prakiraan}

Mengetahui ketepatan yang dihasilkan berdasarkan perhitungan dan simulasi dengan menggunakan metode Mean absolute deviation(MAD), Mean squared deviation(MSD), Root Mean Square Error (RMSE) dan Mean absolute percentage error (MAPE).

\section{Mean absolute deviation (MAD)}

Mean absolute deviation (MAD) adalah rata rata kesalahan mutlak selama periode tertentu tanpa memperhatikan apakah hasil peramalan lebih besar atau lebih kecil dibanding kenyataannya, dengan kata lain MAD adalah rata-rata dari nilai absolut simpangan (Makridakis et.al., 1997). Secara sistematis MAD dirumuskan sebagai berikut:

$M A D=\frac{\sum_{t=1}^{n}\left|A_{t}-F_{t}\right|}{n}$

Keterangan: $\mathrm{A}_{\mathrm{t}} \quad=$ Nilai Aktual

$\mathrm{F}_{\mathrm{t}} \quad=$ Nilai Prakiraan

$\mathrm{n} \quad=$ Jumlah Data

\section{Mean Square Error (MSE)}

Mean Square Error (MSE) merupakan perhitungan dengan menjumlahkan kuadrat semua kesalahan peramalan pada setiap periode dan membaginya dengan jumlah periode peramalan [6]. Secara sistematis MSE dirumuskan sebagai berikut:

$$
M S E=\frac{\sum_{t=1}^{n}\left(A_{t}-F_{t}\right)^{2}}{n}
$$

\section{Root Mean Square Error (RMSE)}

Root Mean Square Error (RMSE) adalah metode alternatif untuk mengevaluasi teknik peramalan yang digunakan untuk mengukur tingkat akurasi hasil prakiraan suatu model. RMSE merupakan nilai ratarata dari jumlah kuadrat kesalahan, juga dapat menyatakan ukuran besarnya kesalahan yang dihasilkan oleh suatu model prakiraan. Nilai RMSE rendah menunjukkan bahwa variasi nilai yang dihasilkan oleh suatu model prakiraan mendekati variasi nilai obeservasinya. Secara sistematis RMSE dirumuskan sebagai berikut:

$$
R M S E=\frac{\sqrt{\sum_{t=1}^{n}\left(A_{t}-F_{t}\right)^{2}}}{n}
$$

\section{Mean Absolute Percentage Error (MAPE)}

Mean Absolute Percentage Error (MAPE) merupakan ukuran kesalahan relatif. MAPE biasanya lebih berarti dibandingkan MAD karena MAPE menyatakan persentase kesalahan hasil peramalan terhadap permintaan aktual selama periode tertentu yang akan memberikan informasi persentase kesalahan terlalu tinggi atau terlalu rendah, dengan kata lain MAPE merupakan rata-rata kesalahan mutlak selama periode tertentu yang kemudian dikalikan 100\% agar mendapatkan hasil secara persentase (Gaspersz, 2008). Secara sistematis MAPE dirumuskan sebagai berikut: 
$M A P E=\frac{\sum_{t=1}^{n}\left|\frac{A_{t}-F_{t}}{A_{t}}\right|}{n} \times 100$

\section{Hasil Penelitian dan Pembahasan}

A. Hasil Prakiraan Jumlah Pelanggan Energi Listrik Menggunakan Model DKL 3.2

Prakiraan jumlah pelanggan energi listrik dengan perhitungan model DKL 3.2 dapat dilihat pada Tabel 1.

Tabel 1 Hasil Prakiraan Jumlah Pelanggan Energi Listrik Provinsi Jambi 2019-2040 Menggunakan Model DKL 3.2

\begin{tabular}{|c|c|c|c|c|c|}
\hline \multicolumn{6}{|c|}{ Prakiraan Jumlah Pelanggan Energi Listrik Provinsi Jambi 2019-2025 Menggunakan Model DKL 3.2 } \\
\hline Tahun & Rumah Tangga & Bisnis & Industri & Publik & Total \\
\hline 2019 & 505.930 & 35.477 & 314 & 13.270 & 554.992 \\
\hline 2020 & 558.648 & 40.869 & 358 & 13.672 & 613.548 \\
\hline 2021 & 616.859 & 47.081 & 408 & 14.087 & 678.435 \\
\hline 2022 & 681.136 & 54.237 & 465 & 14.514 & 750.351 \\
\hline 2023 & 752.110 & 62.481 & 529 & 14.953 & 830.074 \\
\hline 2024 & 830.480 & 71.978 & 603 & 15.407 & 918.468 \\
\hline 2025 & 917.016 & 82.919 & 687 & 15.873 & 1.016 .495 \\
\hline 2026 & 1.012 .569 & 95.522 & 782 & 16.354 & 1.125 .228 \\
\hline 2027 & 1.118 .079 & 110.041 & 891 & 16.850 & 1.245 .861 \\
\hline 2028 & 1.234 .583 & 126.767 & 1.015 & 17.361 & 1.379 .725 \\
\hline 2029 & 1.363 .226 & 146.035 & 1.156 & 17.887 & 1.528 .303 \\
\hline 2030 & 1.505 .274 & 168.232 & 1.316 & 18.429 & 1.693 .251 \\
\hline 2031 & 1.662 .124 & 193.802 & 1.499 & 18.987 & 1.876 .413 \\
\hline 2032 & 1.835 .317 & 223.260 & 1.708 & 19.563 & 2.079 .847 \\
\hline 2033 & 2.026 .557 & 257.194 & 1.945 & 20.155 & 2.305 .852 \\
\hline 2034 & 2.237 .724 & 296.287 & 2.216 & 20.766 & 2.556 .994 \\
\hline 2035 & 2.470 .895 & 341.322 & 2.524 & 21.395 & 2.836 .136 \\
\hline 2036 & 2.728 .362 & 393.201 & 2.875 & 22.044 & 3.146 .483 \\
\hline 2037 & 3.012 .658 & 452.967 & 3.275 & 22.712 & 3.491 .611 \\
\hline 2038 & 3.326 .577 & 521.816 & 3.730 & 23.400 & 3.875 .523 \\
\hline 2039 & 3.673 .206 & 601.130 & 4.249 & 24.109 & 4.302 .694 \\
\hline 2040 & 4.055 .954 & 692.500 & 4.839 & 24.840 & 4.778 .133 \\
\hline
\end{tabular}

Hasil dari perhitungan pada Tabel 1 menunjukkan adanya peningkatan yang sangat signifikan dari tahun 2019 dengan total pelanggan sebanyak 554.992 pelanggan menjadi 4.778 .133 pelanggan pada tahun 2040 dengan rata-rata total pertumbuhan pelanggan energi listrik di provinsi jambi dari tahun 2019 hingga tahun 2040 adalah 10,80\% per tahun. Rata-rata pertumbuhan setiap sektor pemakai yaitu sektor rumah tangga sebesar 10,42\%, sektor indutri sebesar 13,90\%, sektor bisnis sebesar 15,20\% dan sektor publik sebesar $3,03 \%$. 
B. Hasil Prakiraan Konsumsi Energi Lisrtrik Menggunakan Model DKL 3.2

Prakiraan jumlah konsumsi energi listrik dengan perhitungan model DKL 3.2 dapat dilihat pada Tabel 2.

Tabel 2 Prakiraan Konsumsi Energi Listrik Provinsi Jambi 2019-2040 Menggunakan Model DKL 3.2

\begin{tabular}{|c|c|c|c|c|c|}
\hline \multicolumn{7}{|c|}{ KONSUMSI ENERGI MODEL DKL 3.2 (GWH) } \\
\hline Tahun & Rumah Tangga & Bisnis & Industri & Publik & Jumlah \\
\hline 2019 & 807,44 & 299,61 & 128,21 & 105,19 & $1.340,45$ \\
\hline 2020 & 925,29 & 320,02 & 139,34 & 113,90 & $1.498,55$ \\
\hline 2021 & $1.060,36$ & 341,81 & 151,43 & 123,34 & $1.676,94$ \\
\hline 2022 & $1.215,13$ & 365,09 & 164,57 & 133,55 & $1.878,35$ \\
\hline 2023 & $1.392,50$ & 389,96 & 178,86 & 144,61 & $2.105,92$ \\
\hline 2024 & $1.595,76$ & 416,52 & 194,38 & 156,58 & $2.363,24$ \\
\hline 2025 & $1.828,69$ & 444,88 & 211,25 & 169,55 & $2.654,37$ \\
\hline 2026 & $2.095,62$ & 475,18 & 229,59 & 183,58 & $2.983,97$ \\
\hline 2027 & $2.401,51$ & 507,54 & 249,51 & 198,79 & $3.357,35$ \\
\hline 2028 & $2.752,05$ & 542,11 & 271,17 & 215,25 & $3.780,57$ \\
\hline 2029 & $3.153,76$ & 579,03 & 294,71 & 233,07 & $4.260,56$ \\
\hline 2030 & $3.614,10$ & 618,46 & 320,29 & 252,37 & $4.805,22$ \\
\hline 2031 & $4.141,64$ & 660,58 & 348,08 & 273,26 & $5.423,57$ \\
\hline 2032 & $4.746,18$ & 705,57 & 378,30 & 295,89 & $6.125,94$ \\
\hline 2033 & $5.438,97$ & 753,62 & 411,13 & 320,39 & $6.924,11$ \\
\hline 2034 & $6.232,88$ & 804,95 & 446,81 & 346,92 & $7.831,56$ \\
\hline 2035 & $7.142,67$ & 859,77 & 485,59 & 375,65 & $8.863,68$ \\
\hline 2036 & $8.185,26$ & 918,32 & 527,74 & 406,75 & $10.038,07$ \\
\hline 2037 & $9.380,04$ & 980,86 & 573,54 & 440,43 & $11.374,88$ \\
\hline 2038 & $10.749,21$ & $1.047,67$ & 623,32 & 476,90 & $12.897,10$ \\
\hline 2039 & $12.318,24$ & $1.119,02$ & 677,42 & 516,39 & $14.631,07$ \\
\hline 2040 & $14.116,29$ & $1.195,23$ & 736,22 & 559,14 & $16.606,88$ \\
\hline
\end{tabular}

Hasil dari perhitungan konsumsi energi listrik pada Tabel 2 menunjukkan adanya peningkatan yang sangat pesat dari tahun 2019 dengan total konsumsi energi listrik sebesar 1340,45 GWh menjadi 16.606,88 GWh pada tahun 2040 dengan rata-rata total pertumbuhan konsumsi energi listrik di provinsi jambi dari tahun 2019 hingga tahun 2025 adalah 12,73\% per tahun. Rata-rata pertumbuhan konsumsi energi listrik setiap sektor pemakai yaitu sektor rumah tangga sebesar $14,60 \%$, sektor indutri sebesar $8,68 \%$, sektor bisnis sebesar 6,81\% dan sektor publik sebesar $8,28 \%$.

C. Hasil Prakiraan Jumlah Pelanggan Energi Listrik Menggunakan Perangkat Lunak LEAP

Prakiraan jumlah pelanggan energi listrik Provinsi Jambi tahun 2019 sampai tahun 2025 disimulasikan dengan perangkat lunak LEAP yang dapat dilihat pada Gambar 1. Variabel data yang digunakan untuk prakiraan jumlah pelanggan yaitu data jumlah pelanggan pada tahun terakhir dimasukan kedalam ekspresi pada cabang permintaan skenario nilai dasar setelah data dimasukan selanjutnya memasukan data pertumbuhan pelanggan kedalam ekspresi cabang permintaan skenario BaU. Hasil simulasi prakiraan jumlah pelanggan dapat dilihat pada Tabel 3. 

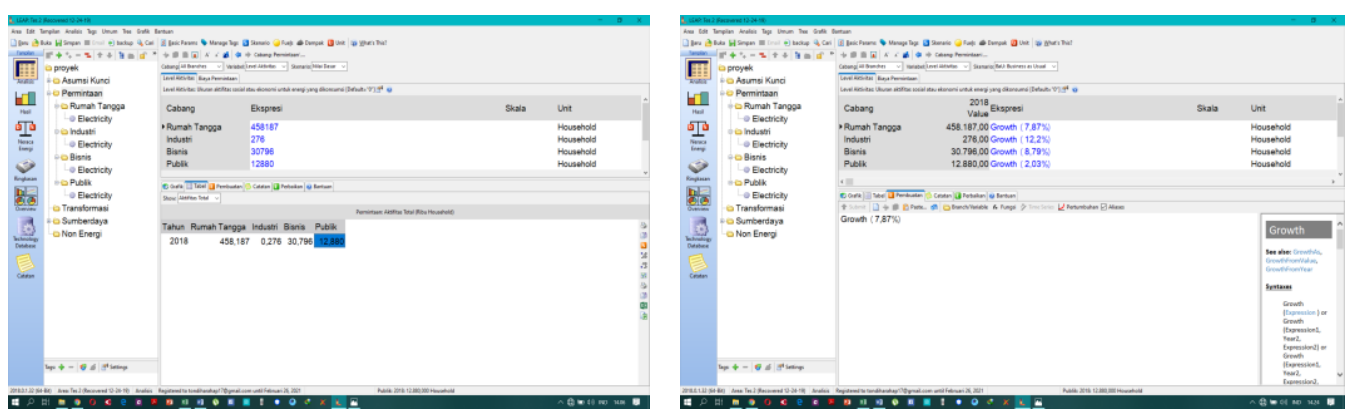

Gambar 1 Tampilan Masukan Variabel Data (Kiri) dan Masukan Data Pertumbuhan Pelanggan (Kanan) ke Perangkat Lunak LEAP

Tabel 3 Hasil Prakiraan Jumlah Pelanggan Energi Listrik Provinsi Jambi 2019-2040 Menggunakan Perangkat Lunak LEAP

\begin{tabular}{|c|c|c|c|c|c|}
\hline \multicolumn{7}{|c|}{ Jumlah Pelanggan Simulasi Perangkat Lunak Leap } \\
\hline Tahun & Rumah Tangga & Bisnis & Industri & Publik & Jumlah \\
\hline 2019 & 494.246 & 33.503 & 309 & 13.141 & 541.200 \\
\hline 2020 & 533.144 & 36.448 & 347 & 13.408 & 583.347 \\
\hline 2021 & 575.102 & 39.652 & 390 & 13.680 & 628.824 \\
\hline 2022 & 620.362 & 43.137 & 437 & 13.958 & 677.895 \\
\hline 2023 & 669.185 & 46.929 & 491 & 14.241 & 730.846 \\
\hline 2024 & 721.850 & 51.054 & 551 & 14.531 & 787.985 \\
\hline 2025 & 778.659 & 55.541 & 618 & 14.826 & 849.644 \\
\hline 2026 & 839.940 & 60.424 & 693 & 15.127 & 916.183 \\
\hline 2027 & 906.043 & 65.735 & 778 & 15.434 & 987.989 \\
\hline 2028 & 977.349 & 71.513 & 873 & 15.747 & 1.065 .481 \\
\hline 2029 & 1.054 .266 & 77.799 & 979 & 16.067 & 1.149 .111 \\
\hline 2030 & 1.137 .237 & 84.637 & 1.099 & 16.393 & 1.239 .365 \\
\hline 2031 & 1.226 .737 & 92.077 & 1.233 & 16.725 & 1.336 .772 \\
\hline 2032 & 1.323 .282 & 100.171 & 1.383 & 17.065 & 1.441 .900 \\
\hline 2033 & 1.427 .424 & 108.976 & 1.552 & 17.411 & 1.555 .362 \\
\hline 2034 & 1.539 .762 & 118.554 & 1.741 & 17.765 & 1.677 .822 \\
\hline 2035 & 1.660 .941 & 128.975 & 1.953 & 18.125 & 1.809 .996 \\
\hline 2036 & 1.791 .657 & 140.312 & 2.192 & 18.493 & 1.952 .655 \\
\hline 2037 & 1.932 .661 & 152.646 & 2.459 & 18.869 & 2.106 .635 \\
\hline 2038 & 2.084 .761 & 166.063 & 2.759 & 19.252 & 2.272 .836 \\
\hline 2039 & 2.248 .832 & 180.660 & 3.096 & 19.643 & 2.452 .231 \\
\hline 2040 & 2.425 .815 & 196.540 & 3.473 & 20.041 & 2.645 .870 \\
\hline & & & & & \\
\hline
\end{tabular}

Hasil dari simulasi pada tabel menunjukkan adanya peningkatan dari tahun 2019 dengan total pelanggan sebanyak 541.200 pelanggan menjadi 2.645 .870 pelanggan pada tahun 2040 dengan rata-rata total pertumbuhan pelanggan energi listrik di provinsi jambi dari tahun 2019 hingga tahun 2040 adalah $7,85 \%$ per tahun. Rata-rata pertumbuhan setiap sektor pemakai yaitu sektor rumah tangga sebesar 7,87\%, sektor indutri sebesar $12,21 \%$, sektor bisnis sebesar $8,79 \%$ dan sektor publik sebesar 2,03\%. 
D. Hasil Prakiraan Konsumsi Energi Lisrtrik Menggunakan Perangkat Lunak LEAP

Prakiraan konsumsi energi listrik Provinsi Jambi tahun 2019 sampai tahun 2040 disimulasikan dengan perangkat lunak LEAP yang dapat dilihat pada Gambar .

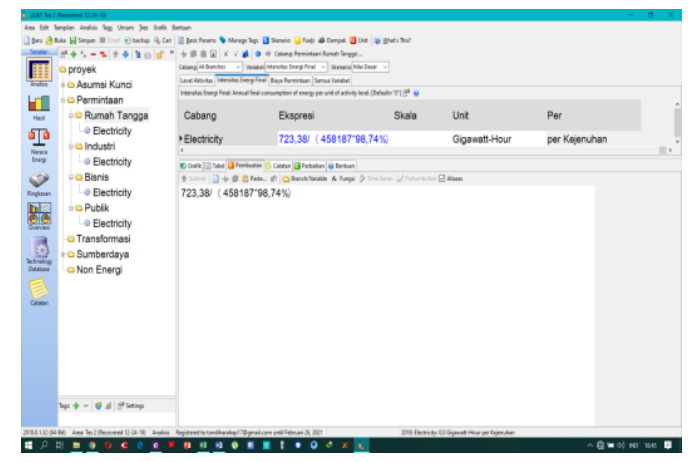

Gambar 2 Tampilan Masukan Variabel Data Konsumsi Energi Listrik ke Perangkat Lunak LEAP

Variabel data yang digunakan untuk prakiraan konsumsi energi listrik yaitu data jumlah pelanggan pada tahun terakhir, rasio elektrifikasi tahun terakhir dan konsumsi energi listrik tahun terakhir. Data dimasukan kedalam ekspresi pada cabang permintaan skenario nilai dasar dan skenario BaU menggunakan persamaan pertumbuhan intensitas energi. Hasil simulasi dapat dilihat pada Tabel 4.

Tabel 4 Prakiraan Konsumsi Energi Listrik Provinsi Simulasi LEAP

\begin{tabular}{|c|c|c|c|c|c|}
\hline \multicolumn{7}{|c|}{ Konsumsi Listrik Simulasi Perangkat Lunak Leap (Gwh) } \\
\hline Tahun & Rumah Tangga & Bisnis & Industri & Publik & Jumlah \\
\hline 2019 & 785,29 & 305,17 & 132,36 & 99,12 & $1.321,94$ \\
\hline 2020 & 852,46 & 331,99 & 148,51 & 101,13 & $1.434,10$ \\
\hline 2021 & 919,55 & 361,17 & 166,63 & 103,19 & $1.550,54$ \\
\hline 2022 & 991,92 & 392,92 & 186,96 & 105,28 & $1.677,08$ \\
\hline 2023 & $1.069,98$ & 427,46 & 209,77 & 107,42 & $1.814,63$ \\
\hline 2024 & $1.154,19$ & 465,03 & 235,36 & 109,60 & $1.964,18$ \\
\hline 2025 & $1.245,03$ & 505,91 & 264,07 & 111,82 & $2.126,83$ \\
\hline 2026 & $1.343,01$ & 550,38 & 296,29 & 114,09 & $2.303,77$ \\
\hline 2027 & $1.448,70$ & 598,75 & 332,44 & 116,41 & $2.496,30$ \\
\hline 2028 & $1.562,72$ & 651,39 & 372,99 & 118,77 & $2.705,87$ \\
\hline 2029 & $1.685,70$ & 708,64 & 418,50 & 121,19 & $2.934,03$ \\
\hline 2030 & $1.818,37$ & 770,93 & 469,55 & 123,65 & $3.182,50$ \\
\hline 2031 & $1.961,47$ & 838,70 & 526,84 & 126,16 & $3.453,16$ \\
\hline 2032 & $2.115,84$ & 912,42 & 591,11 & 128,72 & $3.748,09$ \\
\hline 2033 & $2.282,36$ & 992,62 & 663,23 & 131,33 & $4.069,54$ \\
\hline 2034 & $2.461,98$ & $1.079,87$ & 744,14 & 134,00 & $4.419,99$ \\
\hline 2035 & $2.655,74$ & $1.174,79$ & 834,93 & 136,72 & $4.802,17$ \\
\hline 2036 & $2.864,74$ & $1.278,06$ & 936,79 & 139,49 & $5.219,08$ \\
\hline 2037 & $3.090,20$ & $1.390,40$ & $1.051,08$ & 142,32 & $5.674,00$ \\
\hline 2038 & $3.333,40$ & $1.512,61$ & $1.179,31$ & 145,21 & $6.170,53$ \\
\hline 2039 & $3.595,73$ & $1.645,57$ & $1.323,19$ & 148,16 & $6.712,65$ \\
\hline 2040 & $3.878,72$ & $1.790,22$ & $1.484,62$ & 151,17 & $7.304,72$ \\
\hline
\end{tabular}


Hasil dari simulasi konsumsi energi listrik pada Tabel 4 menunjukkan meningkatnya setiap tahun akan kebutuhan energi listrik dari tahun 2019 dengan total konsumsi energi listrik sebesar 1.321,94 GWh menjadi 7.304,72 GWh pada tahun 2040 dengan rata-rata total pertumbuhan pelanggan energi listrik di provinsi jambi dari tahun 2019 hingga tahun 2040 adalah 8,48\% per tahun. Rata-rata pertumbuhan setiap sektor pemakai yaitu sektor rumah tangga sebesar 7,90\%, sektor indutri sebesar $12,20 \%$, sektor bisnis sebesar $8,79 \%$ dan sektor publik sebesar 2,03\%.

E. Ketepatan Prakiraan Perhitungan dan Simulasi Jumlah Pelanggan

Ketepatan pada model DKL 3.2 dan simulasi perangkat lunak LEAP dapat diketahui dengan menggunakan persamaan (17)-(20), dimana data pada tahun 2012 hingga 2014 digunakan sebagai prakiraan jumlah pelanggan tahun 2015 hingga 2018. Kemudian dari hasil prakiraan dan data aktual akan dihitung tingkat ketepatannya menggunakan persamaan tersebut. Hasil perhitungan ketepatan model DKL 3.2 dan simulasi perangkat lunak LEAP terhadap data aktual dapat dilihat pada Tabel 5 dan 6. Selnajutnya, hasil MAD, MSE, RMSE dan MAPE jumlah pelanggan dapat dilihat Tabel 7.

Tabel 5 Perhitungan Ketepatan Jumlah Pelanggan Model DKL 3.2

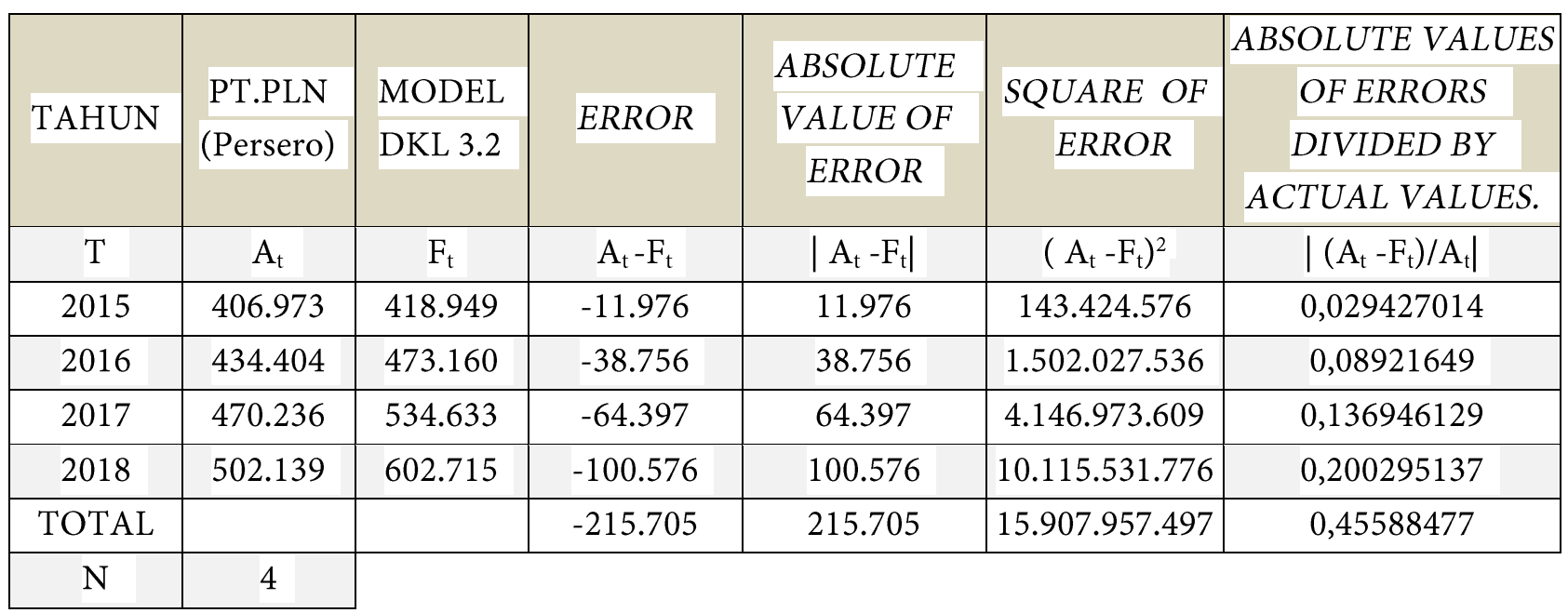

Tabel 6 Perhitungan Ketepatan Jumlah Pelanggan Simulasi LEAP

\begin{tabular}{|c|c|c|c|c|c|c|}
\hline TAHUN & $\begin{array}{c}\text { PT.PLN } \\
(\text { Persero })\end{array}$ & LEAP & ERROR & $\begin{array}{c}\text { ABSOLUTE } \\
\text { VALUE OF } \\
\text { ERROR }\end{array}$ & $\begin{array}{c}\text { SQUARE } \\
\text { OF ERROR }\end{array}$ & $\begin{array}{c}\text { ABSOLUTE VALUES } \\
\text { OF ERRORS } \\
\text { DIVIDED BY } \\
\text { ACTUAL VALUES. }\end{array}$ \\
\hline $\mathrm{T}$ & $\mathrm{A}_{\mathrm{t}}$ & $\mathrm{F}_{\mathrm{t}}$ & $\mathrm{A}_{\mathrm{t}}-\mathrm{F}_{\mathrm{t}}$ & $\mathrm{A}_{\mathrm{t}}-\mathrm{F}_{\mathrm{t}} \mid$ & $\left(\mathrm{A}_{\mathrm{t}}-\mathrm{F}_{\mathrm{t}}\right)^{2}$ & $\left|\left(\mathrm{~A}_{\mathrm{t}}-\mathrm{F}_{\mathrm{t}}\right) / \mathrm{A}_{\mathrm{t}}\right|$ \\
\hline 2015 & 406.973 & 401.566 & 5.407 & 5.407 & 29.235 .649 & 0,013285894 \\
\hline 2016 & 434.404 & 434.564 & -160 & 160 & 25.600 & 0,000368321 \\
\hline 2017 & 470.236 & 470.311 & -75 & 75 & 5.625 & 0,000159494 \\
\hline 2018 & 502.139 & 509.041 & -6.902 & 6.902 & 47.637 .604 & 0,013745198 \\
\hline TOTAL & & & -1.730 & 12.544 & 76.904 .478 & 0,027558907 \\
\hline $\mathrm{N}$ & 4 & & & & &
\end{tabular}


Tabel 7 Hasil MAD, MSE, RMSE dan MAPE Jumlah Pelanggan antara Model DKL 3.2 dan Simulasi Perangkat Lunak LEAP

\begin{tabular}{|c|c|c|}
\hline ERROR & MODEL DKL 3.2 & LEAP \\
\hline MAD & $53.926,25$ & 3.136 \\
\hline MSE & $3.976 .989 .374,25$ & $19.226 .119,50$ \\
\hline RMSE & $63.063,37$ & $4.384,76$ \\
\hline MAPE & $11,40 \%$ & $0,69 \%$ \\
\hline
\end{tabular}

Dari hasil perhitungan ketepatan model DKL 3.2 didapatkan nilai MAD sebesar 53.926,25, nilai MSE sebesar 3.976.989.374,25, nilai RMSE sebesar 63.063,37, dan nilai MAPE sebesar 11,40\% sedangkan hasil simulasi LEAP didapatkan nilai MAD sebesar 3.136, nilai MSE sbesar 19.226.119,50, nilai RMSE sebesar 4.384,76, dan nilai MAPE sebesar 0,69\%. Hasil tersebut menunjukan nilai error terkecil dimiliki prakiraan menggunakan simulasi perangkat lunak LEAP ini dikarenakan prakiraan jumlah pelanggan pada perangkat lunak LEAP hanya memperhitungkan pertumbuhan rata-rata di setiap sektornya, sedangkan prakiraan jumlah pelanggan menggunakan model DKL 3.2 memperhitungkan aspek pertumbuhan PDRB.

F. Ketepatan Prakiraan Perhitungan dan Simulasi Konsumsi Energi Listrik

Hasil perhitungan ketepatan pada model DKL 3.2 dan simulasi perangkat lunak LEAP untuk konsumsi energi listrik sama seperti mencari ketepatan prakiraan jumlah pelanggan, dimana data pada tahun 2012 hingga 2014 untuk digunakan sebagai prakiraan jumlah pelanggan tahun 2015 hingga 2018. Kemudian dari hasil prakiraan dan data aktual akan dihitung tingkat ketepatannya menggunakan persamaan (17)-(20). Hasil perhitungan ketepatan model DKL 3.2 dan simulasi perangkat lunak LEAP terhadap data aktual konsumsi energi listrik dapat dilihat pada Tabel 8 dan 9. Selanjutnya, hasil MAD, MSE, RMSE dan MAPE konsumsi energi listrik model DKL 3.2 dan simulasi perangkat lunak LEAP dapat dilihat Tabel 10.

Tabel 8 Perhitungan Ketepatan Konsumsi Energi Listrik Model DKL 3.2

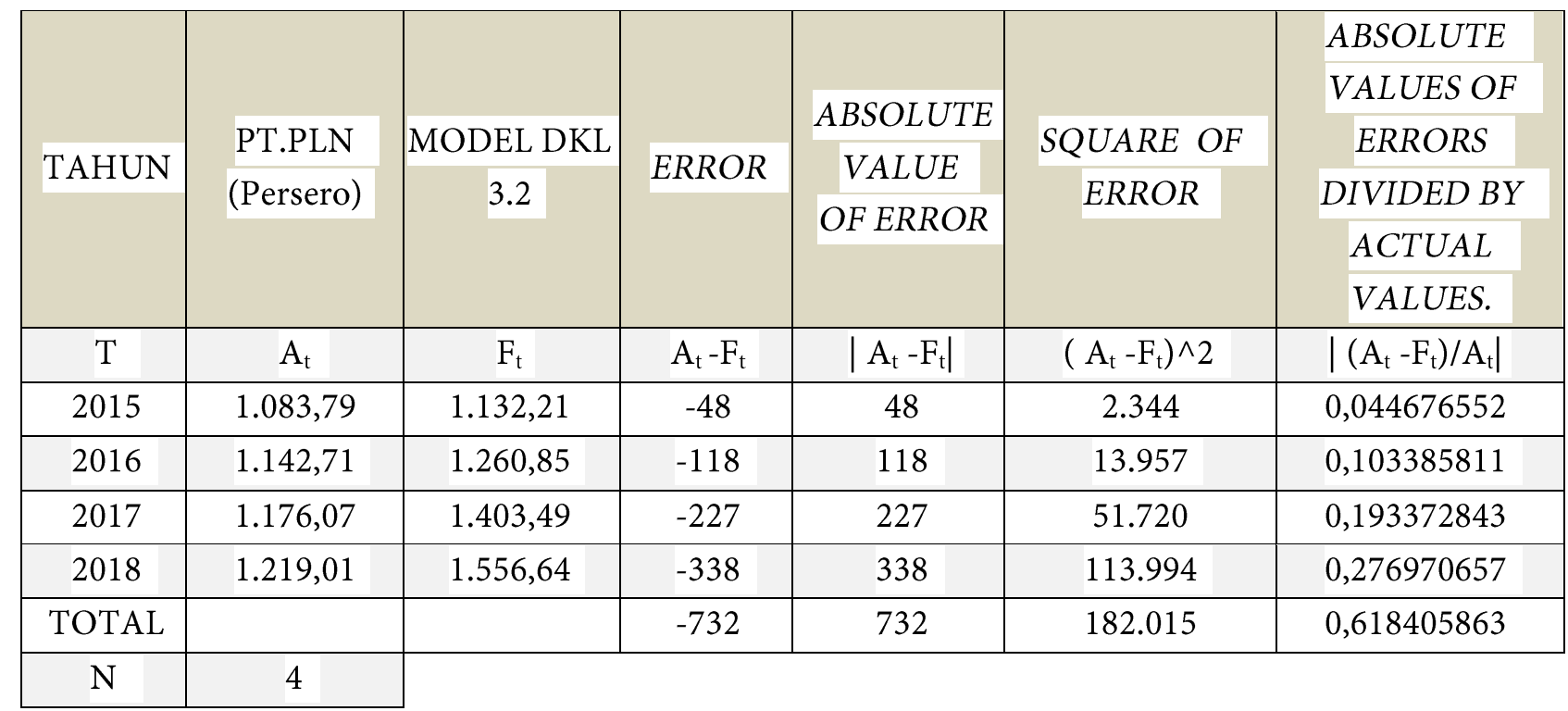


Tabel 9 Perhitungan Ketepatan Konsumsi Energi Listrik Simulasi Perangkat Lunak LEAP

\begin{tabular}{|c|c|c|c|c|c|c|}
\hline TAHUN & $\frac{\text { PT.PLN }}{\text { (Persero) }}$ & LEAP & ERROR & $\begin{array}{c}\text { ABSOLUTE } \\
\text { VALUE OF } \\
\text { ERROR }\end{array}$ & $\begin{array}{c}\text { SQUARE OF } \\
\text { ERROR }\end{array}$ & $\begin{array}{c}\text { ABSOLUTE } \\
\text { VALUES OF } \\
\text { ERRORS } \\
\text { DIVIDED BY } \\
\text { ACTUAL } \\
\text { VALUES. }\end{array}$ \\
\hline $\mathrm{T}$ & $A_{t}$ & $\mathrm{~F}_{\mathrm{t}}$ & $A_{t}-F_{t}$ & $\left|A_{t}-F_{t}\right|$ & $\left(A_{t}-F_{t}\right) \wedge 2$ & $\left|\left(A_{t}-F_{t}\right) / A_{t}\right|$ \\
\hline 2015 & $1.083,79$ & $1.133,98$ & -50 & 50 & 2.519 & 0,046309709 \\
\hline 2016 & $1.142,71$ & $1.239,75$ & -97 & 97 & 9.417 & 0,084920934 \\
\hline 2017 & $1.176,07$ & $1.355,67$ & -180 & 180 & 32.256 & 0,152711998 \\
\hline 2018 & $1.219,01$ & $1.482,69$ & -264 & 264 & 69.527 & 0,216306675 \\
\hline TOTAL & & & -591 & 591 & 113.719 & 0,500249317 \\
\hline $\mathrm{N}$ & 4 & & & & & \\
\hline
\end{tabular}

Tabel 10 Hasil MAD, MSE, RMSE dan MAPE Konsumsi Energi Listrik antara Model DKL 3.2 dan Simulasi Perangkat Lunak LEAP

\begin{tabular}{|c|c|c|}
\hline ERROR & MODEL DKL 3.2 & LEAP \\
\hline MAD & 182,90 & 147,63 \\
\hline MSE & $45.503,86$ & $28.429,78$ \\
\hline RMSE & 213,32 & 168,61 \\
\hline MAPE & $15,46 \%$ & $12,51 \%$ \\
\hline
\end{tabular}

Dari hasil perhitungan ketepatan model DKL 3.2 didapatkan nilai MAD sebesar 182,90, nilai MSE sebesar 45.503,86, nilai RMSE sebesar 213,32, dan nilai MAPE sebesar 15,46\% sedangkan hasil simulasi LEAP didapatkan nilai MAD sebesar 147,63, nilai MSE sbesar 28.429,78, nilai RMSE sebesar 168,61, dan nilai MAPE sebesar 12,51\%. Hasil tersebut menunjukan nilai error terkecil dimiliki prakiraan menggunakan simulasi perangkat lunak LEAP tetapi selisihnya tidak terlalu besar ini dikarenakan didalam LEAP yang disimulasikan adalah intensitas energi untuk memprakirakan konsumsi energi listrik, sedangkan prakiraan konsumsi energi listrik menggunakan model DKL 3.2 yang memperhitungkan aspek pertumbuhan PDRB beserta elastisitas setiap sektornya dan pada sektor rumah tangga memperhitungkan unit konsumsi beserta delta pelanggan rumah tangga.

G. Pemenuhan Kebutuhan Energi Listrik dari Model DKL 3.2 dan Simulasi Perangkat Lunak LEAP

Setelah melakukan prakiraan terhadap pelanggan energi listrik dan konsumsi energi listrik Provinsi Jambi tahun 2019-2040 selanjutnya dilakukan prakirakan ketersediaan kapasitas pembangkit untuk memenuhi energi listrik dari tahun 2019-2040. 
Data pembangkit di Provinsi Jambi tahun 2018, disimulasikan pada perangkat lunak LEAP cabang tranformasi untuk memprakirakan ketersediaan kapasitas dari pembangkit-pembangkit tersebut hingga tahun 2040. Setelah pembangkit-pembangkit tersebut disimulasikan pada LEAP maka akan diketahui sampai tahun berapa pembangkit tersebut dapat memenuhi kebutuhan energi listrik yang telah dihitung berdasarkan model DKL 3.2 dan perangkat lunak LEAP. Data yang akan di masukan pada perangkat lunak LEAP cabang transformasi adalah rugi-rugi daya dan total kapasitas setiap jenis pembangkit. Rugi-rugi daya dimasukan pada cabang transformasi bagian proses transmisi dan distribusi kemudian untuk total kapasitas setiap jenis pembangkit dimasukan pada cabang transformasi bagian proses pembangkit listrik. Masukan data kedalam perangkat lunak LEAP dapat dilihat pada Gambar 3.
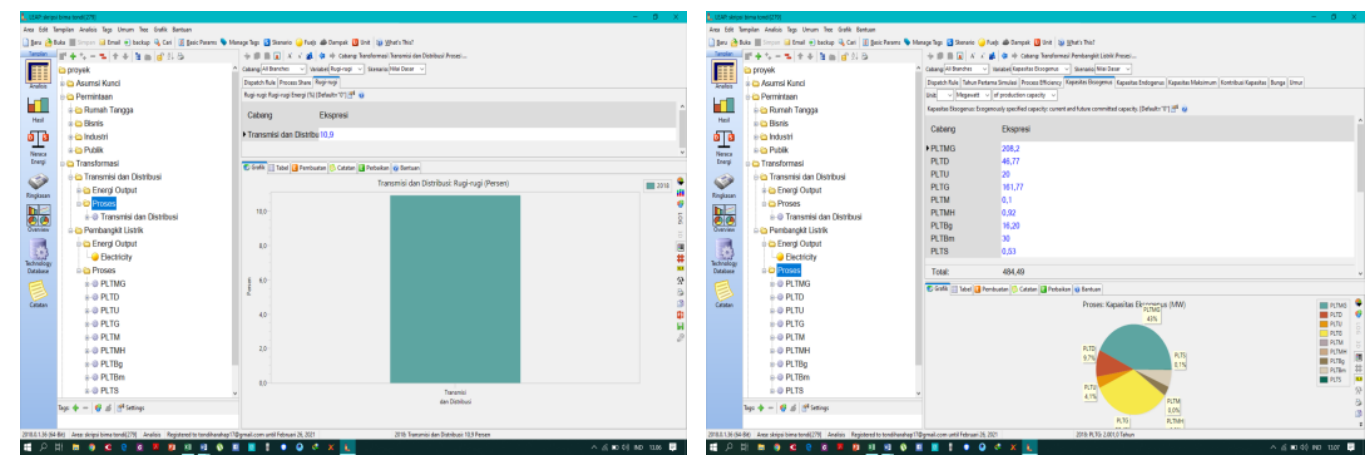

Gambar 3 Masukan Data Rugi-Rugi Daya (Kiri) dan Masukan Data Total Kapasitas Setiap Jenis Pembangkit (Kanan) pada Perangkat Lunak LEAP

Pada masukan data total kapasitas akan ada masukan data lainnya seperti dispatch rule, tahun pertama simulasi, proses efisiensi, kapasitas eksogenus, kapasitas endogenus, kapasitas maksimum, kontribusi kapasitas, bunga dan umur. dispatch rule adalah mengeset penggunaan kapasitas. Pada dispatch rule masukan pada ekspresinya adalah "ProportionalToCapacity" yang berarti pangsa output mengikuti pangsa kapasitas yang tersedia, maksudnya adalah simulasi yang akan dihitung berdasarkan kapasitas eksogenus atau kapasitas yang tersedia saat ini. Tahun simulasi pertama adalah set tahun simulasi akan dimulai, jika set pada tahun dasarnya 2019 maka nilai data produksi historisis setiap pembangkit tahun 2018 harus dimasukan tetapi jika nilai data produksi historisis setiap pembangkit tidak tersedia set nilai dasar tahun simulasi pertama dibawah tahun parameter dasar yaitu dibawah tahun 2018 maka simulasi berdasarkan kapasitas eksogenus, apabila data proses efiensi setiap pembangkit dan data produksi historisis setiap pembangkit tersedia maka pada dispatch rule masukan pada ekspresinya adalah "PercentShare" yang berarti pangsa output ditentukan. Masukan ekspresi pada cabang transformasi pembangkit listrik dapat dilihat pada 4.
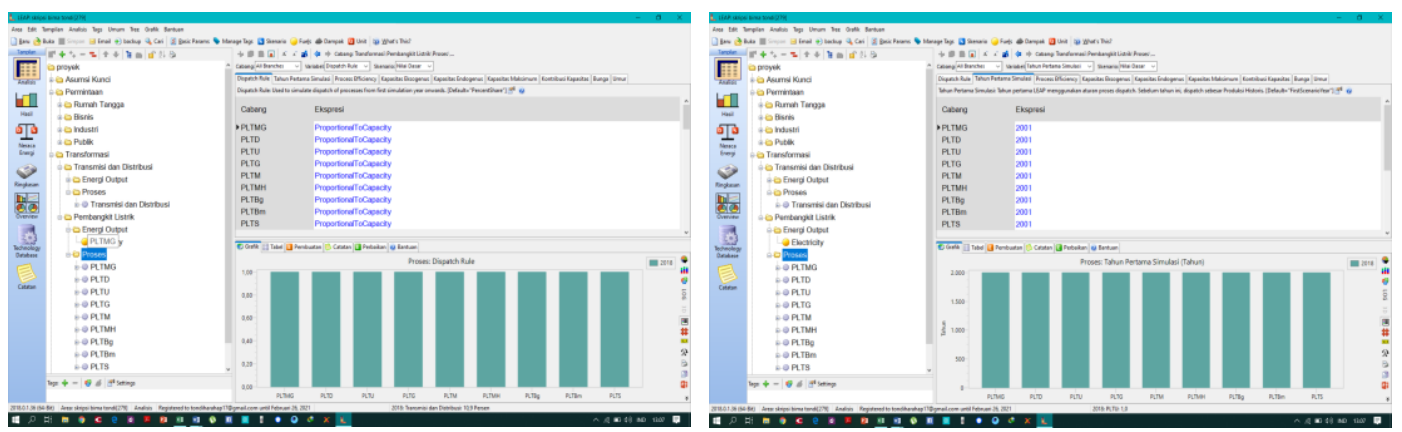

Gambar 4 Masukan Ekspresi Nilai Dasar Dispatch Rule Proses Pembangkit Listrik (Kiri) dan Masukan Ekspresi Tahun Pertama Simulasi Proses Pembangkit Listrik (Kanan) 
Hasil simulasi kapasitas pembangkit dapat dilihat pada Tabel 12 .

Tabel 12 Data Simulasi Ketersediaan Energi Listrik Tahun 2019-2040

\begin{tabular}{|c|c|c|c|}
\hline \multicolumn{4}{|c|}{ Ketersediaan Energi Listrik (Gwh) } \\
\hline Tahun & Output & Kebutuhan Domestik & Unmet Requirements \\
\hline 2019 & 1.483 & -1.484 & 0 \\
\hline 2020 & 1.610 & -1.610 & 0 \\
\hline 2021 & 1.740 & -1.740 & 0 \\
\hline 2022 & 1.882 & -1.882 & 0 \\
\hline 2023 & 2.037 & -2.037 & 0 \\
\hline 2024 & 2.204 & -2.204 & 0 \\
\hline 2025 & 2.387 & -2.387 & 0 \\
\hline 2026 & 2.586 & -2.586 & 0 \\
\hline 2027 & 2.802 & -2.802 & 0 \\
\hline 2028 & 3.037 & -3.037 & 0 \\
\hline 2029 & 3.293 & -3.293 & 0 \\
\hline 2030 & 3.572 & -3.572 & 0 \\
\hline 2031 & 3.876 & -3.876 & 0 \\
\hline 2032 & 4.207 & -4.207 & 0 \\
\hline 2033 & 4.244 & -4.567 & 323 \\
\hline 2034 & 4.244 & -4.961 & 717 \\
\hline 2035 & 4.244 & -5.390 & 1.146 \\
\hline 2036 & 4.244 & -5.858 & 1.613 \\
\hline 2037 & 4.244 & -6.368 & 2.124 \\
\hline 2038 & 4.244 & -6.925 & 2.681 \\
\hline 2039 & 4.244 & -7.534 & 3.290 \\
\hline 2040 & 4.244 & -8.198 & 3.954 \\
\hline
\end{tabular}

Pada tabel 12 dapat dianalisa bahwa energi listrik yang tersedia dari pembangkit hanya mampu menyediakan energi listrik sebesar 4.244 GWh sedangkan permintaan energi listrik yang dibutuhkan sebesar $4.567 \mathrm{GWh}$ dengan kekurangan energi listrik sebesar $323 \mathrm{GWh}$ pada tahun 2033 dan pada tahun 2040 kekurangan energi listrik sebesar 3.954 GWh. Dari hasil simulasi menyatakan kekurangan energi listrik tersebut akan disediakan melalui impor energi listrik. Hasil keseimbangan energi yang telah disimulasikan dapat dilihat pada Tabel 13 dan Gambar 5. 
Tabel 13 Data Simulasi Keseimbangan Energi Tahun 2033

\begin{tabular}{|c|c|c|c|c|c|c|c|c|}
\hline & $\begin{array}{c}\text { Solid } \\
\text { Fuels }\end{array}$ & $\begin{array}{c}\text { Natural } \\
\text { Gas }\end{array}$ & $\begin{array}{c}\text { Hydro } \\
\text { power }\end{array}$ & Renewables & $\begin{array}{c}\text { Bio } \\
\text { mass }\end{array}$ & Electricity & $\begin{array}{c}\text { Oil } \\
\text { Products }\end{array}$ & Total \\
\hline Impor & 175,2 & $3.240,9$ & 271,7 & 4,6 & 141,9 & 323,2 & 409,7 & $4.567,4$ \\
\hline $\begin{array}{c}\text { Pemasokan } \\
\text { Primer Total }\end{array}$ & 175,2 & $3.240,9$ & 271,7 & 4,6 & 141,9 & 323,2 & 409,7 & $4.567,4$ \\
\hline $\begin{array}{c}\text { Pembangkit } \\
\text { Listrik }\end{array}$ & $-175,2$ & $-3.240,9$ & $-271,7$ & $-4,6$ & $-141,9$ & $4.244,1$ & $-409,7$ & $-0,0$ \\
\hline $\begin{array}{c}\text { Transmisi dan } \\
\text { Distribusi }\end{array}$ & - & - & - & - & - & $-497,8$ & - & $-497,8$ \\
\hline $\begin{array}{c}\text { Transformasi } \\
\text { Total }\end{array}$ & $-175,2$ & $-3.240,9$ & $-271,7$ & $-4,6$ & $-141,9$ & $3.746,3$ & $-409,7$ & $-497,8$ \\
\hline Rumah Tangga & - & - & - & - & - & $2.282,4$ & - & $2.282,4$ \\
\hline Bisnis & - & - & - & - & - & 992,6 & - & 992,6 \\
\hline Industri & - & - & - & - & - & 663,2 & - & 663,2 \\
\hline Publik & - & - & - & - & - & 131,3 & - & 131,3 \\
\hline $\begin{array}{c}\text { Permintaan } \\
\text { Total }\end{array}$ & - & - & - & - & - & $4.069,5$ & - & $4.069,5$ \\
\hline
\end{tabular}

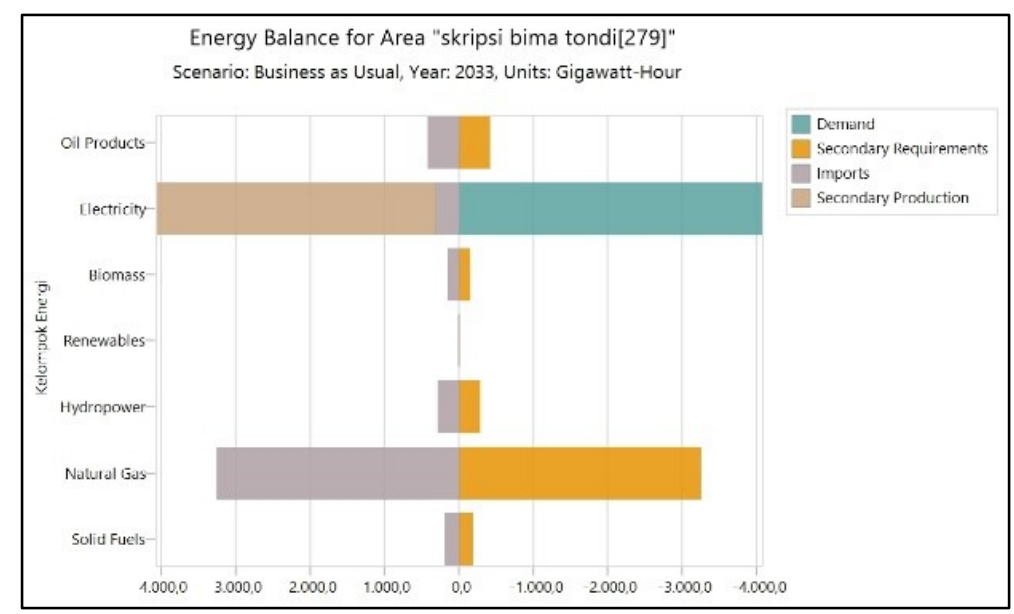

Gambar 5 Grafik Keseimbangan Energi pada Tahun 2033

Dari hasil yang disimulasikan, dapat disimpulkan bahwa Provinsi Jambi perlu mempersiapkan kebutuhan energi listrik untuk memenuhi permintaan energi listrik dimasa yang akan datang agar tidak terjadi kekurangan energi listrik ataupun terjadi pengimporan energi listrik yang akan mempengaruhi finansial dari pemerintah ataupun penyedia energi listrik. Salah satu persiapan agar pengimporan atau kekurangan energi listrik tidak terjadi adalah membangun pembangkit-pembangkit baru untuk mencegah pengimporan energi listrik. Potensi pembangunan pembangkit yang ada di Provinsi Jambi (Pemprov Jambi, 2019) dapat menjadi solusi kepada pemerintah Provinsi Jambi agar dapat terealisasikan pada waktu yang tepat dalam menyediakan energi listrik sebelum terjadinya kekurangan atau pengimporan energi listrik di Provinsi Jambi. 


\section{Kesimpulan dan Saran}

A. Kesimpulan

Dari penelitian yang telah dilakukan, dapat ditarik beberapa kesimpulan sebagai berikut:

1. Jumlah pertumbuhan total pelanggan energi listrik pada tahun 2019-2040 terus mengalami kenaikan, untuk model DKL 3.2 dengan rata-rata pertumbuhan setiap tahunnya sebesar 10,80\%, sedangkan untuk simulasi perangkat lunak LEAP dengan rata-rata setiap tahunnya sebesar $7,85 \%$. Jumlah pertumbuhan konsumsi energi listrik pada tahun 2019-2040 terus mengalami kenaikan yang sangat signifikan, untuk model DKL 3.2 rata-rata total pertumbuhan setiap tahunnya sebesar $12,73 \%$, sedangkan untuk simulasi perangkat lunak LEAP rata-rata total pertumbuhan setiap tahunnya sebesar $8,48 \%$.

2. Kedua metode prakiraan yang dibandingkan dengan perhitungan ketepatan error MAD, MSE, RMSE dan MAPE tersebut mempunyai perbandingan yang sangat besar yaitu untuk prakiraan jumlah pelanggan model DKL 3.2 dengan nilai MAD sebesar 53.926,25, MSE sebesar 3.976.989.374,25, RMSE sebesar 63.063,37 dan MAPE sebesar 11,40\%, sedangkan dalam untuk prakiraan jumlah pelanggan model simulasi perangkat lunak LEAP dengan nilai MAD sebesar 3.136, MSE sebesar 19.226.119,50, RMSE sebesar 4.384,76 dan MAPE sebesar 0,69\%. Ketepatan untuk prakiraan konsumsi energi listrik model DKL 3.2 dengan nilai MAD sebesar 182,90, MSE sebesar 45.503,86, RMSE sebesar 213,32 dan MAPE sebesar 15,46\%, sedangkan dalam untuk prakiraan konsumsi energi listrik simulasi perangkat lunak LEAP dengan nilai MAD sebesar 147,63, MSE sebesar 28.429,78, RMSE sebesar 168,61 dan MAPE sebesar 12,51\%.

3. Hasil prakiraan jumlah pelanggan dan konsumsi listrik dapat menjadi acuan agar persedian energi listrik tercukupi dan tidak melakukan pengimporan energi listrik. Salah satu caranya pembangunan potensi pembangkit baru seperti PLTU 1.212 MW, PLTGU 60 MW, PLTA 350 MW, PLTM atau PLTMH 15 MW, PLTP 255 MW, PLTG 193 MW dan jenis pembangkit lainnya. Potensi pembangkitpembangkit tersebut dapat menjaga ketersediaan energi listrik hingga tahun 2040.

B. Saran

Untuk penelitian selanjutnya agar dapat melakukan perhitungan dengan banyak metode agar mendapatkan perbandingan yang lengkap dan untuk penelitian yang menggunakan perangkat lunak LEAP agar dapat memperhitungkan aspek dampak ataupun finansialnya agar hasil yang lebih akurat.

\section{Daftar Pustaka}

[1] PT. Perusahaan Listrik Negara (Persero), "Statistik PLN 2018," Sekretariat Perusahaan PT. PLN (Persero), Jakarta, 2019.

[2] Kementerian Energi Sumber Daya Mineral Direktorat Jenderal Ketenagalistrikan, "Statistik Ketenagalistrikan Tahun 2018," Sekretariat Jenderal Ketenagalistrikan, Jakarta, 2019.

[3] J. Heizer and B. Render, Operations Management, 10 ed., 2011, p. 890\890.

[4] R. K. Dewayana P, H. and K. , "Proyeksi Kebutuhan dan Penyediaan Energi Listrik di Jawa Tengah Menggunakan Perangkat Lunak LEAP," 2011.

[5] Suhono. "Kajian Perencanaan Permintaan Dan Penyediaan Energi Listrik Di Wilayah Kabupaten Sleman Menggunakan Perangkat Lunak Leap," Universitas Gajah Mada, Yogyakarta, 2010.

[6] S. G. Makridakis, S. C. Wheelwright and R. J. Hyndman, Forecasting: Methods And Applications, vol. 3 edition, New Jersey: Wiley India, 1997. 
[7] V. Gaspersz, Production Planning And Inventory Control, Jakarta: PT. Gramedia Pustaka Utama, 2008.

[8] Peraturan Rencana Umum Energi Daerah Provinsi Jambi, Rencana Umum Energi Daerah Provinsi Jambi Nomor 13 Tahun 2019, Jambi: Pemerintah Daerah provinsi Jambi, 2019. 